\title{
SAÚDE DO TRABALHADOR \& TERCEIRIZAÇÃO: PERFIL DE TRABALHADORES DE SERVIÇO DE LIMPEZA HOSPITALAR ${ }^{1}$
}

Manuela de Santana Pi Chillida ${ }^{2}$ Maria Inês Monteiro Cocco ${ }^{3}$

Chillida MSP, Cocco MIM. Saúde do trabalhador \& terceirização: perfil de trabalhadores de serviço de limpeza hospitalar. Rev Latino-am Enfermagem 2004 março-abril; 12(2):271-6.

Nas duas últimas décadas, a terceirização de serviços possibilitou a redução dos custos das empresas, pela racionalização de suas ações e exploração de relações precárias do trabalho. Esta pesquisa teve por objetivo traçar o perfil dos trabalhadores terceirizados, que atuavam no serviço de limpeza de um hospital universitário, identificar suas perspectivas em relação ao processo saúde-doença e ao seu futuro. Trata-se de um estudo descritivo, de abordagem quantitativa, com amostragem aleatória, com 50 trabalhadores. A maioria começou a trabalhar precocemente, $74 \%$ eram do sexo feminino e com baixa escolaridade. Dos entrevistados, 36\% referiram doenças diagnosticadas pelo médico. No período estudado, $84 \%$ dos trabalhadores entrevistados realizaram consultas médicas, totalizando 181 consultas, resultando em média 3,6 consultas por trabalhador, sendo a mais freqüente, 56\%, com o clínico geral. A análise dos dados possibilitou a identificação das perspectivas desses profissionais em relação ao processo saúde/doença e ao seu futuro.

DESCRITORES: saúde ocupacional; trabalho feminino; serviços terceirizados; serviço de limpeza

\section{WORKER'S HEALTH \& OUTSOURCING: WORKER'S PROFILE} IN A HOSPITAL CLEANING SERVICE

In the last two decades, service outsourcing has reduced companies' costs by the rationalization of their actions and the exploration of precarious work relations. This research aimed to outline the profile of outsourced workers in the cleaning service of a university hospital, identify their points of view about the health-illness process and future plans. This is a descriptive study from a quantitative approach, involving a random sample with 50 cleaning workers. Most of them started to work early, $74 \%$ were women and education level was low. In $36 \%$ of the cases, physicians diagnosed some kind of illness. In the analyzed period, $84 \%$ of the interviewees had realized medical consultations, resulting in an average of 3.6 consultations per worker, $56 \%$ of which involved general clinicians. Data analysis allowed for the identification of these professionals' perspectives in relation to the health - illness process and their future.

DESCRIPTORS: occupational health; female work; outsourced services; cleaning service

\section{SALUD DEL TRABAJ ADOR \& SERVICIO DE TERCEROS: \\ PERFIL DE LOS TRABAJ ADORES TERCERIZADOS DE UN SERVICIO DE LIMPIEZA HOSPITALARIA}

En las últimas décadas el servicio de terceros posibilitó la reducción de los costos de las compañías, por la racionalización de sus acciones y exploración de relaciones precarias de trabajo. Este estudio tuvo por objetivo analizar el perfil de los trabajadores del servicio de terceros, que actúan en el servicio de limpieza de un hospital universitario en el interior del Estado de San Paulo. Es un estudio descriptivo con abordaje cuantitativo con 50 trabajadoras. Esta población se caracterizó por empezar a trabajar temprano siendo $74 \%$ del sexo femenino, también se destaca la baja escolaridad. De los 50 entrevistados, $36 \%$ refirieron dolencias diagnosticadas por el médico. En el periodo estudiado, $84 \%$ de los trabajadores entrevistados realizaron consultas médicas, totalizando 181 consultas, resultando en promedio 3,6 consultas/trabajador, siendo la más frecuente, 56\%, con un clínico general. El análisis de los datos posibilitó la identificación de las perspectivas de estos profesionales con relación al proceso salud/enfermedad y el futuro.

DESCRIPTORES: salud ocupacional; trabajo de mujeres; servicios externos; servicio de limpieza

\footnotetext{
${ }^{1}$ Projeto financiado pelo PIBIC-CNPq; ${ }^{2}$ Mestranda em Enfermagem; ${ }^{3}$ Professor Associado, Coordenador do Grupo de Estudos e Pesquisas em Saúde e Trabalho, Orientador da pesquisa, e-mail: inesmon@obelix.unicamp.br. Faculdade de Ciências Médicas da Universidade Estadual de Campinas
} 
A terceirização pode ser definida como "o ato de

$\boldsymbol{A}$ constante renovação tecnológica, política, social, econômica e cultural tem levado a grandes mudanças no setor de serviços, refletindo em diversas transformações na organização do trabalho. "A reestruturação produtiva e industrial consiste em um processo que compatibiliza mudanças institucionais e organizacionais nas relações de produção e de trabalho, bem como redefinição de papéis dos Estados nacionais e das instituições financeiras"(1).

A reestruturação produtiva começou a se delinear mais nitidamente no final da década de setenta, redefinindo as estratégias do capital no que diz respeito às relações de trabalho, abrindo novas linhas de investigação. Nesse novo contexto, estudar as transformações do trabalho significa observá-las sob diversos ângulos, considerando que, para compreender a atual conjuntura mundial, é preciso considerar uma sociedade global, com extraordinário crescimento do desemprego, em meio a profundas transformações estruturais.

"Não há um movimento generalizado de desqualificação ou um movimento de aumento geral da qualificação, mas um movimento contraditório de desqualificação do trabalho de alguns pela 'superqualificação' do trabalho de outros, isto é, uma polarização das qualificações requeridas que resulta de uma forma particular de divisão do trabalho, que se caracteriza por uma modificação da repartição social da 'inteligência' da produção. Uma parte dessa 'inteligência' é 'incorporada' às máquinas, e a outra parte é distribuída entre um grande número de trabalhadores, graças à atividade de um número restrito de pessoas encarregadas da tarefa (impossível) de pensar previamente a totalidade do processo de trabalho, descobrindo e possuindo o domínio do conjunto de parâmetros"(2).

Verifica-se, principalmente nos países desenvolvidos e em áreas industrializadas do Brasil, um processo de reestruturação na produção, nas formas organizacionais e no mercado de trabalho. "Os novos processos de trabalho que emergem do atual processo de reorganização produtiva, ao induzir a flexibilização da estrutura ocupacional, recriam formas precárias de atividade produtiva e de trabalho. Ao fazê-lo, desarticulam a composição dicotômica que preponderava nos mercados de trabalho daqueles países que, em geral, podia ser sintetizada nas situações de emprego e desemprego"(3). transferir a responsabilidade de um serviço, ou de determinada fase da produção ou comercialização, de uma empresa para outra"(4). Isso possibilita que a empresa centre-se na realização de algumas ações, havendo racionalização e conseqüente aumento da produtividade. "No entanto, a terceirização tem sido mais uma tática de redução de custos, pela exploração de relações precárias do trabalho, do que uma redução dos custos baseados no aumento da eficiência e da produtividade"(4).

Os caminhos recentemente traçados para o estudo da relação trabalho e saúde têm se definido pela pluralidade metodológica em direção à interdisciplinaridade, configurando possibilidades mais concretas de aproximação da realidade. Esses caminhos adquirem novos contornos no encontro de problemas atuais e antigos, mas que são colocados diariamente pelo universo do trabalho, pela área da saúde, pelos movimentos sociais no Brasil e em todo cenário nacional.

A participação das mulheres no mercado de trabalho é dada não somente "... pelas condições do mercado, pela estrutura do emprego ou pelo nível de desenvolvimento da sociedade, mas também por sua posição na família e pela classe social à qual pertence 0 grupo doméstico. Filha, esposa ou mãe, a cada etapa do ciclo de vida familiar, corresponderão a determinadas necessidades e possibilidades de trabalho que, dadas as oportunidades oferecidas pelo mercado, definirão a situação da mulher em relação às atividades produtivas”(5).

"O trabalho doméstico e a educação dos filhos ficavam, apesar das lutas femininas, e creio que ainda ficam, de certo modo, relegados à categoria não-trabalho, de atividades inerentes a sua condição feminina e que, no entanto, implicam desgaste físico, mental e um grande número diário de horas trabalhadas, para um grande contingente de mulheres, no Brasil”(6).

A situação das trabalhadoras de serviços gerais no mercado de trabalho traz à tona tanto sua condição de profissionais sem qualificação formal e submetidas à disciplina e à lógica das relações capitalistas, essencialmente no que diz respeito à disponibilidade de uso dessa mão-de-obra por parte do capital, como sua condição de mulheres, cujos papéis caracterizam-se pela sua subordinação às relações de dominação masculinas, expressas no âmbito doméstico ou no trabalho assalariado.

Estudos recentes sobre o trabalho feminino têm 
demonstrado o modo como as mulheres são discriminadas no mercado de trabalho. "Além de ocuparem os piores empregos, de estarem sujeitas às condições de trabalhos mais precárias e de receberem os piores salários, as mulheres são também mais instáveis no mercado de trabalho, detendo menos oportunidades de promoção e treinamento"(7). O trabalho que não exige qualificação profissional tem sido estudado por outros autores, como em relação aos acidentes de trabalho de varredores de rua $^{(8)}$.

\section{OBJETIVOS}

Traçar o perfil dos trabalhadores terceirizados que atuam no serviço de limpeza de um hospital universitário em relação à escolaridade e rotatividade no serviço.

Identificar a percepção e perspectivas desses profissionais em relação ao processo saúde-doença e ao seu futuro.

\section{METODOLOGIA}

Esta pesquisa descritiva, com abordagem quantitativa, foi realizada junto aos trabalhadores terceirizados do serviço de limpeza de um hospital universitário público, do interior do Estado de São Paulo.

A empresa terceirizada apresentava, em agosto de 1999, um quadro de 206 funcionários, sendo duas enfermeiras, três supervisores, dez encarregados e 191 trabalhadores de serviços gerais.

A amostra foi definida em cerca de $25 \%$ do total de trabalhadores de serviços gerais, 50 indivíduos, que atuavam no setor. Foi realizada uma amostra aleatória dos trabalhadores, distribuídos proporcionalmente nos quatro horários de trabalho: 06:00 às 14:20h, 13:40 às 22:00h, 06:45 às 16:48h, 22:00 às 06:00h.

Os critérios de inclusão foram: trabalhar no serviço terceirizado de limpeza e aceitar participar da pesquisa.

A coleta de dados foi realizada por meio de entrevista semi-estruturada, e o instrumento utilizado nesta pesquisa já havia sido testado durante a realização da tese de doutoramento "Reestruturação produtiva e o setor saúde: trabalhadores de enfermagem em saúde coletiva"(6)

Além dos dados coletados por meio da entrevista, foi realizada a observação de dois períodos de trabalho desses profissionais, em diferentes áreas de trabalho.

Para a montagem do banco de dados e sua posterior análise, foi utilizado o programa computacional EPI-INFO 6.

O projeto de pesquisa foi aprovado pelo Comitê de Ética da Faculdade de Ciências Médicas da UNICAMP. Foi utilizado o termo de consentimento livre e esclarecido.

\section{RESULTADOS}

A idade média dos trabalhadores estudados foi de 36,52 anos, variando entre 23 e 57 anos de idade. A distribuição por faixa etária foi a seguinte: $16 \%$, entre $20 \mathrm{e}$ 29 anos; $50 \%$,entre 30 e 39 anos; 26\%, entre 40 e 49 anos, e $8 \%$, com 50 anos de idade ou mais.

Em relação à escolaridade, $8 \%$ da amostra não freqüentaram a escola, $64 \%$ tinham escolaridade entre a 1a e a $7^{\text {a }}$ série do ensino fundamental; $10 \%$ estavam cursando o ensino fundamental supletivo; $2 \%$ tinham o ensino médio incompleto, e $6 \%$ concluíram o ensino médio.

Dos trabalhadores entrevistados, $74 \%$ eram do sexo feminino, enquanto que apenas $26 \%$ eram do sexo masculino.

A maior parte desses trabalhadores (46\%) começou a trabalhar na infância, e 32\% entre 12-16 anos (adolescência); $12 \%$ de 17 a 21 anos, $4 \%$ dos 22 aos 26; $4 \%$ dos 27 aos 31 , e $2 \%$ dos 32 aos 38 anos de idade.

Em relação ao tempo de serviço, foi constatado que grande parte dos trabalhadores entrevistados (44\%), trabalhava há menos de um ano na instituição, demonstrando o elevado índice de rotatividade no serviço. Os trabalhadores com dois a quatro anos totalizaram $36 \%$; entre cinco e seis anos, $12 \%$, e somente $8 \%$ entre nove e dez anos.

Quando questionados sobre se há relação entre trabalho e saúde, apenas $60 \%$ dos trabalhadores entrevistados afirmaram que o trabalho afetava a sua saúde.

A perspectiva dos trabalhadores em relação ao fato de o trabalho afetar sua saúde mostra que eles associavam o risco ocupacional aos produtos utilizados para limpeza do piso e equipamentos, ao trabalho repetitivo (possibilidade de desenvolver lesão por esforço repetitivo LER), probabilidade de acidentes com instrumentos perfurocortantes e fluidos biológicos como sangue, fezes, urina, vômito, além de estresse. 
Apenas um entrevistado, membro da Comissão Interna para Prevenção de Acidentes -CIPA, mencionou o uso dos equipamentos de proteção individual (EPI).

Dois entrevistados referiram que o trabalho afetava a saúde de maneira positiva.

Dentre os entrevistados, 36\% afirmaram apresentar problemas de saúde já diagnosticados pelo médico, distribuídos da seguinte forma: doenças respiratórias bronquite, sinusite e rinite; doenças cardiovasculares hipertensão, sopro, estenose mitral e hipercolesterolemia; doenças músculo-esqueléticas - tendinite, problemas de coluna; doença mental leve - depressão; anemia, infecção urinária, dermatite e diabetes (Tabela 1).

Tabela 1 - Distribuição das doenças com diagnóstico médico entre trabalhadores terceirizados do serviço de limpeza no último ano. Campinas, 2000

\begin{tabular}{lcc}
\hline Doenças $^{*}$ & N & $\%$ \\
\hline Doenças respiratórias & 9 & 29,2 \\
Doenças cardiovasculares & 8 & 25,8 \\
Doenças músculo-esqueléticas & 3 & 9,6 \\
Doença mental leve & 3 & 9,6 \\
Doenças do sangue & 2 & 6,5 \\
Doença genitourinária & 1 & 3,2 \\
Doença digestiva & 1 & 3,2 \\
Doença da pele & 1 & 3,2 \\
Doença endócrina e metabólica & 1 & 3,2 \\
Outras doenças & 2 & 6,5 \\
Total & 31 & 100,0 \\
\hline
\end{tabular}

* Mais que uma doença diagnosticada por trabalhador

Entre os anos de 1999 e 2000, 84\% dos trabalhadores entrevistados passaram por uma ou mais consultas médicas. O número total de consultas foi de 181, resultando, em média, 3,6 consultas por trabalhador, nos últimos doze meses.

As especialidades médicas procuradas para consulta foram: clínica geral, ginecologia, oftalmologia, dermatologia, cardiologia, ortopedia, psiquiatria e urologia; sendo que o maior número de consultas, $56 \%$, foi com o clínico geral.

Quando questionados sobre os planos e perspectivas para o futuro, apenas $66 \%$ da amostra afirmaram ter planos para o futuro. As mulheres foram mais pessimistas do que os homens, pois apenas $59 \%$ das mulheres tinham planos para o futuro, enquanto que $85 \%$ dos homens responderam afirmativamente.

Os planos traçados por esses trabalhadores estavam relacionados à construção de casa própria, deixar de trabalhar na limpeza do hospital, mudar de emprego e aumento salarial.

Dentre os que disseram não ter planos para o futuro, o conteúdo das respostas abordava aspectos extremamente negativos e pessimistas.

Durante o transcorrer das entrevistas, surgiram diversas questões sobre o falta de tempo desses profissionais para planejar o futuro, realizar atividades de lazer, refletir sobre seu próprio cotidiano, devido à dupla jornada de trabalho (casa e trabalho), além do cuidado com os filhos.

\section{DISCUSSÃO DOS DADOS}

A baixa qualificação profissional dos trabalhadores do serviço de higiene e limpeza pode ser observada durante a realização desta pesquisa, pois a maioria (64\%) tinha o ensino fundamental incompleto, e $8 \%$ eram analfabetos, resultado esperado, tendo em vista que é um trabalho que não exige qualificação profissional.

Em pesquisa realizada sobre os problemas decorrentes da terceirização junto a sindicalistas de 40 empresas, pelo Departamento Intersindical de Estatística e Estudos Socioeconômicos - DIEESE, foi constatada a diminuição salarial, de benefícios sociais, a ausência de equipamentos de segurança do trabalho, a ausência de registro do empregado, a perda da representação sindical e a baixa qualificação desses profissionais ${ }^{(4)}$.

A presença majoritária (74\%) de mulheres já era esperada, pois existe uma segmentação por sexo do mercado de trabalho, e as mulheres estão inseridas nos trabalhos mais precários, com baixos salários e sem condições de progressão profissional ${ }^{(7)}$.

Os dados divulgados no site do Instituto Brasileiro de Geografia e Estatística - IBGE, que têm como referência a Pesquisa Nacional por Amostras de Domicílios - PNAD, mostram que "a taxa de escolarização das meninas ainda supera a dos meninos, embora esse diferencial venha se reduzindo. Em decorrência de a taxa de escolarização feminina ser mais elevada, o nível de instrução das mulheres encontra-se em patamar nitidamente mais alto que o dos homens. Entretanto, a disparidade entre o nível de instrução dos dois gêneros é muito mais acentuada na população ocupada, pois o interesse feminino em ingressar no mercado de trabalho tende a aumentar, com a elevação do seu nível educacional”(9). 
Quando são cruzadas informações sobre a idade desses trabalhadores com o ano em que pararam de estudar, pode-se observar que grande parte (65\%) parou entre 13 e 22 anos, idade avançada, se levarmos em consideração a baixa escolaridade demonstrada por esses trabalhadores que apresentam, em sua maioria, apenas o ensino fundamental (64\%); $14 \%$ pararam de estudar entre os oito e doze anos, e 14\%, entre 23 e 27 anos.

É importante ressaltar, no entanto, que o início precoce do trabalho, em $46 \%$ da amostra, pode ter causado dificuldades para a continuidade dos estudos, pela necessidade de contribuir no orçamento ou no rearranjo doméstico, o que permite a entrada, no mercado, de outros integrantes da família.

Os depoimentos dos trabalhadores ressaltaram a necessidade desse rearranjo doméstico que permite 0 trabalho de outros integrantes da família, cuidando dos irmãos mais novos e da roça da família.

Há uma diferença de sexo em relação à idade de início do trabalho, pois aproximadamente $60 \%$ dos homens e $40 \%$ das mulheres começaram a trabalhar entre 7 e 11 anos, o que, certamente, afetará sua capacidade futura de trabalho.

Para alguns autores, "na medida em que o trabalho doméstico se organiza em termos de empresa capitalista, as relações entre ele e os rendimentos da família tornamse evidentes"(10)

Certamente, há padrões diferentes de incorporação ao mercado de trabalho das mulheres, nas várias classes sociais. As variações encontradas dizem respeito tanto ao modelo de desenvolvimento econômico e ao processo de ampliação das oportunidades de trabalho, quanto às transformações ocorridas na sociedade brasileira, em relação à estrutura familiar e aos padrões culturais.

Durante a idade produtiva, em termos de força de trabalho e em termos de intelecto e reflexão, em função da estrutura econômica e de valores, a mulher está, em geral, absorvida na tarefa de criar os filhos e da manutenção do lar como principais ocupações, mesmo quando trabalha fora de casa. Quando os filhos crescem, é comum que a mulher reflita sobre sua condição de vida, por a "tarefa mais nobre" - o cuidado com os filhos - estar terminando; por insatisfação ou mesmo por necessidade.

Em relação às doenças referidas, com diagnóstico médico, algumas estão relacionadas diretamente ao trabalho desenvolvido, como a tendinite, a dermatite e problemas psiquiátricos decorrentes do trabalho. No entanto, alguns entrevistados associaram as condições de trabalho a outras patologias, como bronquite, rinite e sinusite, que podem ter ocorrido devido ao uso de produtos químicos irritantes para a limpeza de pisos e equipamentos.

Um outro dado importante nessa questão é que os dois indivíduos com diagnóstico de tendinite e de dermatite relacionada aos produtos de limpeza utilizados responderam que o trabalho não afeta a saúde. Isso pode ter ocorrido por esses trabalhadores não associarem o trabalho a esses problemas de saúde diagnosticados, não sabendo a sua causa, ou por medo de que a empresa pudesse ter contato com as respostas fornecidas.

O trabalho executado pelos trabalhadores, no serviço de higiene e limpeza, gera grande desgaste físico e é acrescido, em geral, para a mulher, das atividades da casa e o cuidado com os filhos. Na verdade, o problema de fundo refere-se à dificuldade de apreender a realidade social, o que resulta do paradigma até aqui hegemônico do conhecimento científico e que hoje buscamos superar por meio de abordagens interdisciplinares. A construção e a consolidação de uma nova ciência crítica, dirigida às verdadeiras necessidades da sociedade brasileira, representam, sem dúvida, um desafio para os pesquisadores da área saúde e trabalho, sobretudo considerando as desigualdades existentes no país, a precariedade da atenção às necessidades básicas, as conseqüências da divisão internacional do trabalho e dos riscos ocupacionais, justapondo problemas emergentes a outros, derivados do processo de trabalho.

Em concordância com dados da pesquisa realizada pelo DIEESE ${ }^{(4)}$, que aponta as condições, em geral, desfavoráveis dos serviços terceirizados, foi encontrado que, entre os trabalhadores terceirizados, o salário recebido era menor do que o dos trabalhadores concursados (pertencentes ao quadro de servidores da universidade) que atuavam no mesmo local.

A situação das trabalhadoras de serviços gerais no mercado de trabalho traz à tona tanto sua condição de profissionais sem qualificação formal e submetidas à disciplina e à lógica das relações capitalistas, essencialmente no que diz respeito à disponibilidade de uso dessa mão-de-obra por parte do capital, como sua condição de mulher, cujos papéis caracterizam-se pela sua subordinação às relações de dominação masculina, expressas no âmbito doméstico e no trabalho assalariado. 


\section{CONSIDERAÇÕES FINAIS}

Tendo como referência as entrevistas realizadas com os trabalhadores, procuramos, inicialmente, traçarIhes um perfil, caracterizando sua estrutura familiar e escolaridade. Procurou-se abordar ainda o problema do trabalho doméstico, das responsabilidades que implica e de sua divisão no interior da família, discutindo sua relação com o trabalho na empresa e o problema da dupla jornada de trabalho.

O caráter temporário do emprego, bem como a presença marcante da força de trabalho feminina $-75 \%$ dos entrevistados, definem as características essenciais dos trabalhadores terceirizados, além do início precoce, entre sete e onze anos de idade, no mercado de trabalho. Nos últimos doze meses, $84 \%$ dos trabalhadores entrevistados tinham realizado consultas médicas, em média 3,6 consultas por trabalhador, sendo a mais freqüente, $56 \%$, com o clínico geral.

Os planos traçados por esses trabalhadores em relação ao futuro estavam relacionados a construir casa própria, deixar de trabalhar na limpeza do hospital/mudar de emprego e obter aumento salarial.

Esta pesquisa procurou investigar em que medida o caráter temporário da ocupação dessa força de trabalho está relacionado com o trabalho feminino. Em outros termos, em que medida o trabalho terceirizado constituise como trabalho de mulheres, no qual questões de gênero tornam-se relevantes na explicação dos mecanismos de alocação da mão-de-obra, no processo

\section{REFERÊNCIAS BIBLIOGRÁFICAS}

1. Miranda JC. O papel das novas tecnologias no processo de reestruturação econômica mundial. Indicadores econômicos FEE 1993; 2(1):1-17.

2. Hirata H. Divisão capitalista do trabalho. Tempo Social 1989; 1(2):73-103.

3. Dedecca C, Montagner P. Crise econômica e desempenho Terciário. São Paulo em Perspectiva 1992; 6(3):2-15.

4. Repullo R. Os sindicatos, a terceirização e a saúde dos trabalhadores. Rev Bras Saúde Ocupacional 1997; 85/ 86(23):79-82.

5. Bruschini MCA. Tendências da força de trabalho feminina brasileira nos anos 70 e 80: algumas comparações regionais. São Paulo (SP): Fundação Carlos Chagas; 1989.

6. Cocco MIM. Reestruturação produtiva e o setor saúde: trabalhadores de enfermagem em saúde coletiva. [tese]. Ribeirão Preto (SP): Escola de Enfermagem de Ribeirão Preto/ USP; 1997.

Recebido em: 28.6.2002

Aprovado em: 8.5.2003 de trabalho.

A análise das relações de gênero tem se constituído num particular desafio para diferentes campos de conhecimento, nos últimos anos. A emergência dessa problemática, invisível ao longo do tempo, revela o quanto as condições sociais e políticas impõem limites à ciência. Tal invisibilidade, produto de uma leitura masculina do mundo e apoiada numa suposta neutralidade de gênero, só pôde ser quebrada com o avanço dos movimentos feministas, que propiciaram à ciência a possibilidade de um ponto de vista, capaz de revelar novos problemas e definir novos objetos de investigação.

A caracterização desse segmento de trabalhadores faz-se necessária na medida em que os enfermeiros, em grande parte das empresas limpadoras, assumem como função o gerenciamento do processo de trabalho, garantindo a qualidade do serviço prestado por essas empresas, uma vez que são os responsáveis pelo processo de educação continuada junto a esses trabalhadores. É importante ressaltar que a ampliação do papel do enfermeiro neste setor, deve ocorrer tendo como ponto de partida a ampliação do olhar, que deixa de dirigirse apenas à gerência do processo de trabalho, voltandose, também, ao trabalhador e às suas condições de saúde, advindas do processo de trabalho e do seu cotidiano.

É fundamental que novas pesquisas com trabalhadores terceirizados sejam desenvolvidas, visando dar visibilidade às suas condições de trabalho, vida e saúde, tendo em vista o crescimento dessa parcela de trabalhadores e suas condições desfavoráveis de trabalho.

7. Vargas FEB. Relações sociais de classe e gênero: o trabalho safrista na indústria de conservas de Pelotas. [dissertação]. Porto Alegre (RS): Instituto de Filosofia e Ciências Humanas/UFRGS; 1994.

8. Silveira EAA, Robazzi MLCC, Luis MAV. Varredores de rua: acidentes de trabalho ocorridos na cidade de Ribeirão Preto, Estado de São Paulo, Brasil. Rev Latino-am Enfermagem 1998 janeiro; 6(1):71-9.

9. Instituto Brasileiro de Geografia e Estatística. IBGE Estatística populacional. Disponível em: URL: http:// www.ibge.gov.br/estatística/poulacional.../pnda98). Acessado em 17.mar.2000.

10. Chillida MSP, Cocco MIM. Gênero, trabalho e saúde: aspectos teóricos. Relatório final de pesquisa. Campinas (SP): SAE - Universidade Estadual de Campinas; 1999. 